\title{
Darbepoetin Alpha For the Treatment of Anemia in Systemic Mastocytosis
}

\author{
Pier Paolo Piccaluga ${ }^{1-3}$, Michela Rondoni ${ }^{4}$, Stefano Lazzi ${ }^{5}$, Stefania Paolini ${ }^{1}$ and Giuseppe Visani ${ }^{6}$ \\ ${ }^{1}$ Department of Experimental Diagnostic and Specialty Medicine, Bologna University School of Medicine, Bologna, Italy \\ ${ }^{2}$ Istituto Euro Mediterraneo di Scienza e Tecnologia (IEMEST) Palermo, Italy \\ ${ }^{3}$ Department of Pathology, School of Medicine, Jomo Kenyatta University of Agriculture and Technology, Nairobi, Kenya \\ ${ }^{4}$ Hematology Unit, Ravenna Hospital
}

${ }^{5}$ Department of Medical Biotechnology, Section of Pathology, Siena, Italy

${ }^{6}$ Hematology and Stem Cell Transplantation Center, AORMN, Pesaro, Italy

Received: 眥 January 24, 2019; Published: 眥January 30, 2019

*Corresponding author: Pier Paolo Piccaluga, Department of Experimental, Diagnostic, and Specialty Medicine, Institute of Hematology and Medical Oncology "L\&A Seràgnoli”, Italy

Funding: Supported by AIL Pesaro Onlus (Dr. Visani) and RFO (Ex 60\%) UNIBO (Prof. Piccaluga)

\begin{abstract}
Human systemic mastocytosis (SM) is a rare disease caused by an abnormal mast cells accumulation in various tissues. The most aggressive forms have a rapid course and required treatments to reduce the neoplastic burden and to slacken the progression. Unfortunately, no therapy has been demonstrated efficacy, mostly in the treatment of aggressive systemic mastocytosis (ASM). Supportive treatments include growth factors, transfusions, steroids and anti-histaminic. No data have been reported so far concerning the use of darbepoetin alpha in this setting. Here, we describe a patient affected by ASM who experienced significant improvement of the hemoglobin level with darbepoetin (from $7.8 \mathrm{~g} / \mathrm{dl}$ to $14.7 \mathrm{~g} / \mathrm{dl}$ ). Of note, a previous attempt with erythropoietin alpha did exert a transient response, which was lost before starting darbepoetin. We conclude that darbepoetin alpha might be considered for prospective evaluation within clinical trials in ASM patients with severe anemia.
\end{abstract}

Keywords: Systemic Mastocytosis; Darbepoetin; Anemia

Abbreviations: SM: Systemic Mastocytosis; ASM: Aggressive Systemic Mastocytosis; MCs: Clonal Mast Cells; WHO: World Health Organization; ASM: Aggressive Systemic; MCL: Mast Cell Leukemia; TKI: Tyrosine Kinase Inhibitor; RBC: Red Blood Cells; EPO: Erythropoietin Alpha; Hb: Hemoglobin

\section{Background}

The Systemic mastocytosis (SM) is a rare disease that is characterized by over-proliferation and accumulation in organs and tissues of clonal mast cells (MCs). It usually occurs in adults involving skin, bone marrow, spleen, skeletal system, liver, or lymph nodes. The World Health Organization (WHO) classification divides the disease into cutaneous mastocytosis, systemic mastocytosis, and localized mast cell tumors. On the basis of histomorphologic criteria, clinical parameters, and organ involvement, systemic mastocytosis is further divided into indolent systemic mastocytosis and advanced systemic mastocytosis variants, including aggressive systemic mastocytosis (ASM) and mast cell leukemia (MCL) [1,2]. Constitutional symptoms may be present, their intensity being quite variable, and directly related to tissue infiltration and to chemical mediators release by MCs $[3,4]$. Patients with ASM are marked by the presence of symptoms due to significant organopathy produced by MCs infiltration $[1,2,5]$.

They include cytopenias, osteolysis (or osteoporosis) with pathologic fractures, hepatosplenomegaly with impaired liver function and ascites, and malabsorption. ASM can show a slowly progressing or a rapid clinical course, eventually shifting to MCL $[1,2,5]$. The molecular pathogenesis of SM has been largely studied in the last decade. In particular, gain-of-function point mutations of the activation loop of KIT have been found in the majority of cases [6-8]. These mutations result in ligand-independent, constitutive activation of KIT signaling, thus leading to uncontrolled MCs proliferation and resistance to apoptosis $[6,7,9]$. Of note, the most commonly observed KIT mutation involves the D816 residue 
and make the use of the tyrosine kinase inhibitor (TKI) imatinib mesylate useless, as the drug cannot bind this specific KIT mutant $[10,11]$.

Similarly, second generation TKI such as dasatinib (BristolMayer-Squibb) or nilotinib (Novartis Pharma), although probably more effective than imatinib, demonstrated a relative scarce activity [12-14]. Conversely, the third generation TKI midostaurin (Novartis Pharma) showed a significant activity in both ASM and MCL $[15,16]$. Alternative treatment options are represented by interferon alpha [17] steroids and chemotherapy [18]. Occasionally, successful usage of other agents has been reported [19,20]. Nonetheless, to date, irrespective of the clinical course, treatment of ASM and MCL is definitely challenging. Supportive treatments include growth factors, transfusions, steroids and anti-histaminic [21]. In particular, no data have been reported concerning the use of darbepoetin alpha (Amgen Switzerland AG) in SM patients presenting with anemia. Here, we describe a patient affected by ASM who experienced significant improvement of the hemoglobin $(\mathrm{Hb})$ level with darbepoetin. Of note, a previous attempt with erythropoietin alpha (EPO) did only exert a transient response.

\section{Case Report}

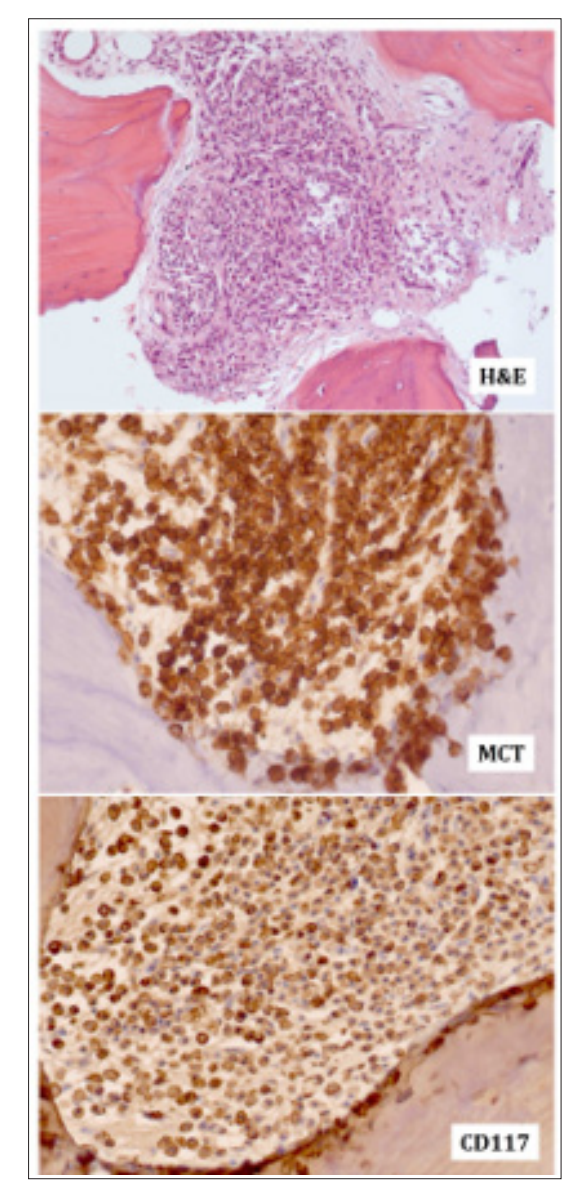

Figure 1: A - Bone marrow infiltration by neoplastic mast cells (10x, Hematoxilin \& Eosin). MCT: Mast cell triptase (20x). CD117: Mast/stem cell growth factor receptor (SCFR/KIT) (20x).
A 79 years-old man was diagnosed for aggressive systemic mastocyosis (ASM) basing on massive bone marrow infiltration by mast cells and splenomegaly. Specifically, bone marrow biopsy showed multifocal clusters of mast cells (Figure 1). At immunohistochemistry, neoplastic cells were CD2+,CD25+, mastcell triptase/MCT+ and CD117/KIT+ (Figure 1). The peripheral blood counts were: Hb $12.2 \mathrm{~g} / \mathrm{dl}$, WBC 8.5x109/L, and PLTs 58x109/L. No cutaneous or further extra-cutaneous involvement was recorded. Imatinib (300 mg/day) was then administered for 1 months without significant response. In addition, the patient developed severe weakness with anemia and worsened thrombocytopenia (PLT=19x109/L). Meanwhile, a mutational analysis of KIT revealed the presence of D186V mutation. Thus, imatinib administration was definitely stopped. Since then, the patient has been requiring periodical red blood cells (RBC) transfusions.

Therefore, he received erythropoietin alpha (80.000 IU/ week for the first two months, and then 40.000 IU/week). The hemoglobin level progressively improved up to $12.2 \mathrm{~g} / \mathrm{dl}$. However, the effect was transitory (Figure 2) and therapy was thus suspended after 10 months, the HB level being dropped down to $7 \mathrm{~g} / \mathrm{dl}$. The patient then received dasatinib, as compassionate, for two months. Splenomegaly and thrombocytopenia did not improve; conversely, the $\mathrm{Hb}$ level further decreased and the clinical condition severely impaired. Thus, dasatinib was suspended and darbepoetin alpha therapy, 150 micro-g/week, was established, with progressive improvement of the $\mathrm{Hb}$ level in the following months up to $14.06 \mathrm{~g} /$ dl. Seven months later, while still on treatment, the patient died as a consequence of major orthopedic surgery, not related to ASM.

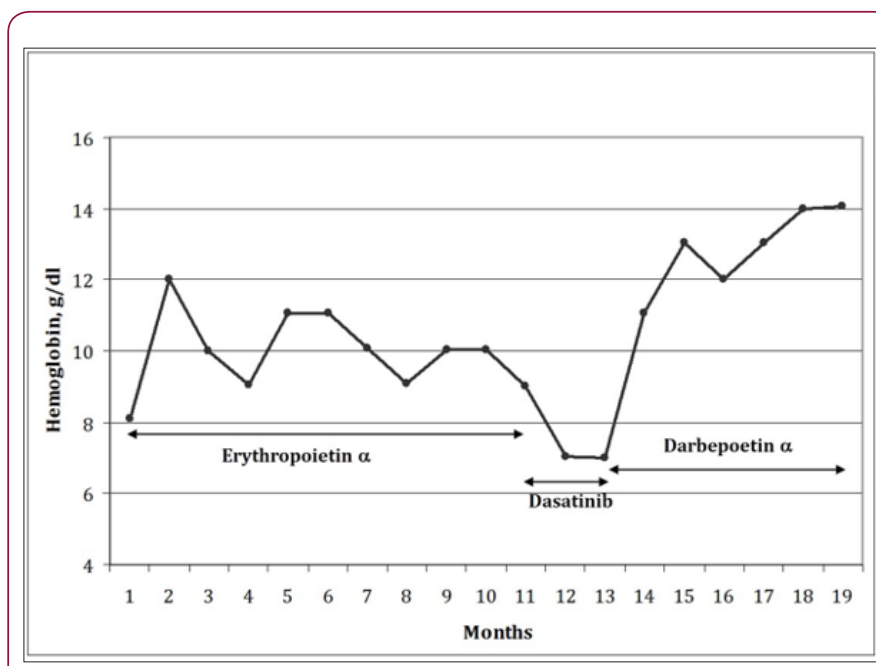

Figure 2: Treatment response in terms of hemoglobin level (g/dl, y axis,) as a function of time (months, $x$ axis).

\section{Discussion}

ASM is a severe disease often characterized by prominent symptoms, poor quality of life, and short survival. Not being available any curative approach, supportive therapy is usually adopted. However, it rarely hesitates in significant clinical benefits [2]. Our case indicated, for the first time, that darbepoetin might be useful in ASM patients with anemia even after failure of conventional EPO 
therapy. In particular, our patient showed a dramatic improvement of the hemoglobin level with darbepoetin, observed after sensitivity to EPO appeared to be lost. Interestingly, it was shown that also patients affected by myelodysplastic syndrome and anemia insensitive to EPO could respond to darbepoetin administration in a significant proportion of cases [22].

The pharmacological determinants of such phenomenon are currently unknown, as the target receptor is common to the two drugs. It is conceivable that a different type of stimulation might overcome the receptor adaptation, but this hypothesis actually need further confirmation. On the other hand, no specific data concerning the use of erythroid growth factors in ASM have been reported so far. Noteworthy, ASM is a rare disease and affected patients constitute an inhomogeneous group with different clinical features. Thus, it has not been easy to design clinical trials and validate possible new approaches, outside cooperative National/International studies, which have been anyway exceptional. Only recently, new TKI showed promising results, even though a potential curative effect still needs to be proved $[13,15,16]$. Unfortunately, when this patient was treated, midostaurin was not available yet. Finally, in our case, a possible therapeutic effect of dasatinib should also be considered. In fact, after two months of therapy, the tripatse level (a surrogate of disease activity) was significantly reduced. However, at the time of the best response to darbepoetin, the tripatse was as high as at baseline again, suggesting that $\mathrm{Hb}$ increase was independent from the possible dasatinib effect. We conclude that darbepoetin might be useful in ASM patients with anemia and, more in general, clinical trials testing erythroid growth factors are warranted in this setting.

\section{References}

1. Pardanani A (2015) Systemic mastocytosis in adults: 2015 update on diagnosis, risk stratification, and management. Am J Hematol Mar 90(3): 250-262.

2. Valent P, Akin C, Hartmann K, Nilsson G, Reiter A, et al. (2017) Advances in the Classification and Treatment of Mastocytosis: Current Status and Outlook toward the Future. Cancer Res 77(6): 1261-1270.

3. Hoermann G, Greiner G, Valent P (2015) Cytokine Regulation of Microenvironmental Cells in Myeloproliferative Neoplasms. Mediators Inflamm 869242

4. Onnes MC, Tanno LK, Elberink JN (2016) Mast Cell Clonal Disorders: Classification, Diagnosis and Management. Curr Treat Options Allergy 3(4): 453-464.

5. Patnaik MM, Rindos M, Kouides PA, Tefferi A, Pardanani A, et al. (2007) Systemic mastocytosis: a concise clinical and laboratory review. Arch Pathol Lab Med 131(5): 784-791.

6. Furitsu T, Tsujimura T, Tono T, Ikeda H, Kitayama H, et al. (1993 ) Identification of mutations in the coding sequence of the proto-oncogene c-kit in a human mast cell leukemia cell line causing ligand-independent activation of c-kit product. J Clin Invest 92(4): 1736-1744.
7. Schumacher J, Elenitoba Johnson K, Lim M (2008) Detection of the c-kit D816V mutation in systemic mastocytosis by allele-specific PCR. J Clin Pathol 61(1): 109:114.

8. Joris $\mathrm{M}$, Georgin-Lavialle $\mathrm{S}$, Chandesris $\mathrm{M}$, Ludovic Lhermitte, Jean François Claisse, et al. (2012) Mast Cell Leukaemia: c-KIT Mutations Are Not Always Positive. Case Rep Hematol (517546).

9. Metcalfe DD, Mekori YA (2017) Pathogenesis and Pathology of Mastocytosis. Annu Rev Pathol 12: 487-514.

10. Pardanani A, Elliott M, Reeder T, Cy Li, EJ Baxter, et al. (2003) Imatinib for systemic mast-cell disease. Lancet 362(9383): 535-536.

11. Ustun C, Arock M, Kluin Nelemans HC, Reiter A, Sperr WR, et al. (2016) Advanced systemic mastocytosis: from molecular and genetic progress to clinical practice. Haematologica 101(10):1133-1443.

12. Verstovsek S, Tefferi A, Cortes J, O Brien S, Garcia Manero G, et al. (2008) Phase II study of dasatinib in Philadelphia chromosome-negative acute and chronic myeloid diseases, including systemic mastocytosis. Clin Cancer Res 14(12): 3906-3015.

13. Hochhaus A, Baccarani M, Giles FJ, le Coutre PD, Müller MC, et al. (2015) Nilotinib in patients with systemic mastocytosis: analysis of the phase 2, open-label, single-arm nilotinib registration study. J Cancer Res Clin Oncol Nov 141(11): 2047-2060.

14. Gotlib J (2017) Tyrosine Kinase Inhibitors in the Treatment of Eosinophilic Neoplasms and Systemic Mastocytosis. Hematol Oncol Clin North Am 31(4): 643-661.

15. Gotlib J, Kluin Nelemans HC, George TI, Cem Akin, Karl Sotlar, et al. (2016) Efficacy and Safety of Midostaurin in Advanced Systemic Mastocytosis. N Engl J Med 374(26): 2530-2541.

16. Stone RM, Manley PW, Larson RA, Capdeville R, et al. (2018) Midostaurin: its odyssey from discovery to approval for treating acute myeloid leukemia and advanced systemic mastocytosis. Blood Adv 2(4): 444453.

17. Kiladjian JJ, Mesa RA, Hoffman R (2011) The renaissance of interferon therapy for the treatment of myeloid malignancies. Blood 117(18): 4706-4715.

18. Pardanani A, Tefferi A (2010) Systemic mastocytosis in adults: a review on prognosis and treatment based on 342 Mayo Clinic patients and current literature. Curr Opin Hematol 17(2): 125-132.

19. Lieberoth S, Thomsen SF (2015) Cutaneous and gastrointestinal symptoms in two patients with systemic mastocytosis successfully treated with omalizumab. Case Rep Med : 903541.

20. Ozdemir D, Dagdelen S, Erbas T, Agbaht K, Serefhanoglu S, et al. (2010) Hypotension, Syncope, and Fever in Systemic Mastocytosis without Skin Infiltration and Rapid Response to Corticosteroid and Cyclosporin: A Case Report. Case Rep Med 782595.

21. Scherber RM, Borate U (2018) How we diagnose and treat systemic mastocytosis in adults. Br J Haematol 180(1): 11-23.

22. Greenberg PL, Sun Z, Miller KB, Bennett JM, Tallman MS, et al. (2009) Treatment of myelodysplastic syndrome patients with erythropoietin with or without granulocyte colony-stimulating factor: results of a prospective randomized phase 3 trial by the Eastern Cooperative Oncology Group (E1996). Blood 114(12): 2393-400. 


\section{ISSN: 2574-1241}

DOI: $10.26717 / B J S T R .2019 .13 .002462$

Pier Paolo Piccaluga. Biomed J Sci \& Tech Res

(C) This work is licensed under Creative

Submission Link: https://biomedres.us/submit-manuscript.php

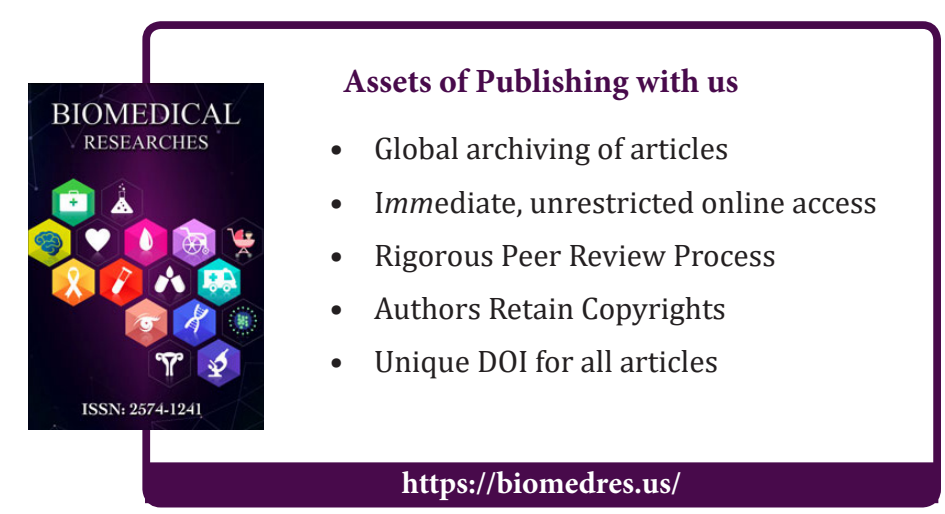

